ВІСНИК

ОДЕСЬКОГО НАЦІОНАЛЬНОГО

МОРСЬКОГО УНІВЕРСИТЕТУ

№ 1 (61), 2020
HERALD

OF THE ODESSA NATIONAL

MARITIME UNIVERSITY

№ 1 (61), 2020

УДК 621.829

DOI 10.47049/2226-1893-2020-1-121-130

\title{
РЕГЕНЕРАЦІЯ ЕКСПЛУАТАЦЙНИХ ВЛАСТИВОСТЕЙ МОТОРНИХ МАСТИЛ СУДНОВИХ ДИЗЕЛІВ
}

\author{
Д.В. Мацкевич \\ кандидат технічних наук, доцент
}

Національний університет «Одеська морська академія»

Анотація. Розглянути питання регенерації експлуатаційних властивостей (в'язкості, кислотного числа, густини) моторних мастил суднових дизелів, щуо використовуються в ииркулячійних системах мащення. Наведені результати експериментальних досліджень 3 визначення зміни вказаних показників, а також реологічної стійкості моторного мастила Castrol TPL 203 під час його експлуатаиії в системі мамення суднового середньообертового дизеля 6ЕY22AW фірми Yanтаr. За результатом виконаних експериментальних досліджень доведено, щз найбільш ефективним способом регенерації експлуатаційних показників моторного мастила є скорочення інтенсивності доливання мастила в загальний обсяг системи мащення з одночасним використанням поверхнево-активної присадки.

Ключові слова: судновий дизель, система мащення, моторне мастило, в'язкість, густина, реологічна стійкість, поверхнево-активна присадка.

УДК 621.829

DOI 10.47049/2226-1893-2020-1-121-130

\section{РЕГЕНЕРАЦИЯ ЭКСПЛУАТАЦИОННЫХ СВОЙСТВ МОТОРНЫХ МАСЕЛ СУДОВЫХ ДИЗЕЛЕЙ}

\author{
Д.В. Мацкевич \\ кандидат технических наук, доцент \\ Национальный университет «Одесская морская академия»
}

\begin{abstract}
Аннотация. Рассмотрены вопросы регенерации эксплуатационных свойств (вязкости, кислотного числа, плотности) моторных масел, используюшихся в ичиркуляиионных системах смазывания судовых дизелей. Приведенные результаты экспериментальных исследований по определению изменения указанных показателей, а также реологической стойкости моторного масла Castrol TPL 203 при его эксплуатаџии в системе ииркуляиионного смазывания судового среднеоборотного дизеля 6EY22AW фирмы Yanmar.
\end{abstract}

(C) Мацкевич Д.В., 2020 
По результатам выполненных экспериментальных исследований доказано, что наиболее эффективным способом регенерации эксплуатационных показателей моторного масла является сокращение времени добавления масла в общий объем системы смазывания с одновременным использованием поверхностно-активных присадок.

Ключевые слова: судовой дизель, система цииркуляциионного смазывания, моторные масла, вязкость, плотность, реологическая стойкость, поверхностно-активная присадка.

UDC 621.829

DOI 10.47049/2226-1893-2020-1-121-130

\title{
REGENERATION OF OPERATIONAL PROPERTIES OF MARINE DIESEL ENGINE OILS
}

\author{
D. Matskevich \\ Candidate of Technical Sciences, Associate Professor \\ National University «Odessa Maritime Academy»
}

\begin{abstract}
It is noted that the operation of marine internal combustion engines provides continuous and periodic monitoring not only of the indicators that characterize the duty cycle of the diesel (pressure and temperature at characteristic points, speed, power, exhaust gas temperature), but also the operational and rheological characteristics of engine oil. The main parameters of engine oil, the control of which is mandatory during the operation of the diesel engine are: viscosity, density, acid number, flash point, water content and mechanical impurities. It is stated that due to the increase of pressure and temperature of the duty cycle, increase of torque, change of design, complication of operating conditions, increase of the working time of modern diesels at maximum loads, the operating conditions of oils in lubricating and circulating lubrication systems have become more stringent. Therefore, it is urgent to solve the problem of regeneration of the operational characteristics of the oil during its operation. Considering the above, the issues of regeneration of operational properties (viscosity, acid number, density) of motor oils used in circulating lubrication systems of marine diesel engines are considered. The results of experimental studies to determine the change in these parameters, as well as the rheological resistance of Castrol TPL 203 engine oil during its operation in the circulating lubrication system of the ship medium-speed diesel engine 6EY22AW of Yanmar. According to the results of experimental studies, it is proved that the most effective way of regenerating the performance of engine oil is to reduce the time of adding oil to the total volume of the lubrication system with the simultaneous use of surfactants. It is established that the reduction of the time of replenishment of the volume of oil in the circulatory system contributes to a slower deviation of its basic
\end{abstract}


qualitative indicators from the base value (above all the viscosity, which increases by 11,76\% when changing the intensity of addition from 100 to 25 hours). Reducing the time to replenish the volume of oil in the circulation system to 10 hours with the simultaneous use of surface-active additives provides an increase in viscosity by 3,92\% while maintaining other indicators (rheological resistance, density and acid number) in the range of recommended and possible values.

Keywords: marine diesel, circulating lubrication system, engine oils, viscosity, density, rheological resistance, surface additive.

Постановка проблеми в загальному вигляді. Під час експлуатації двигунів внутрішнього згоряння (ДВЗ) морських і річкових суден здійснюється безперервний і періодичний контроль не тільки показників, що характеризують робочий цикл дизеля (тиску і температури в характерних точках, частоти обертання, потужності, температури випускних газів), але також експлуатаційних і реологічних характеристик моторного мастила [1]. При цьому основними параметрами, контроль яких обов'язковий у процесі експлуатації дизеля, є: в'язкість, густина, кислотне число, температура спалаху, зміст води і механічних домішок. У процесі експлуатації ці параметри постійно змінюються, причому в деяких випадках можуть перевищувати гранично допустимі значення (бракувальні показники). Це неминуче призводить до збільшення контактних напруг в основних трибологічних системах і підвищення втрат енергії, що витрачається на їхнє подолання [2].

Аналіз останніх досліджень і публікацій. У зв'язку зі збільшенням тиску і температури циклу, підвищенням крутного моменту, зміною конструкції, ускладненням умов експлуатації, підвищенням часу роботи сучасних дизелів на максимальних навантаженнях умови роботи мастил як в лубрикаторних, так і в циркуляційних системах мащення, стали більш жорсткими. Водночас терміни заміни мастил безперервно збільшуються завдяки поліпшенню їх експлуатаційних властивостей. Передчасна заміна мастил економічно недоцільна, оскільки збільшується їх витрата, витрати на технічне обслуговування, запасні частини і т.д. 3 іншого боку, збільшення терміну служби мастил призводить до підвищеного зносу деталей дизеля, що знижує його надійність, збільшує відмови в роботі, сприяє підвищенню незворотних втрат енергії. Визначення оптимальної періодичності заміни мастил $є$ трудомісткою тривалою роботою, спочатку визначається заводом-виробником, коригується за результатами експлуатації та тягне за собою фінансові та експлуатаційні вит-рати [3; 4]. Тому актуальним є розв'язання завдання регенерації експлуатаційних характеристик мастила в процесі його експлуатації [5].

Періодичне додавання мастила в процесі експлуатації частково відновлює його первинні властивості, перш за все це відноситься до таких параметрів, як: в'язкість, кислотне число, температура спалаху. Однак, 
незважаючи на можливе відновлення реологічних характеристик, через певний час моторне мастило підлягає повній заміні. Періодичність такої заміни залежить від властивостей і характеристик мастила; типу, технічного стану та умов експлуатації дизеля; технічного стану всіх компонентів системи мащення; способу фільтрації мастила; використовуваного палива та інших чинників [6; 7]. Необхідність повної заміни зумовлена втратою основних експлуатаційних властивостей моторного мас-тила, тобто його старінням.

Постановка завдання. Повна заміна мастила в суднових умовах вимагає виведення двигуна 3 експлуатації, причому цей період включає не тільки саму процедуру заміни мастила, але й очищення поверхонь тертя від експлуатаційних забруднень. Виконання цього завдання для головних двигунів відбувається під час стоянки судна і може бути заздалегідь заплановано з урахуванням рейсового завдання, характеристик вантажу i майбутніх вантажних операцій. У зв’язку з постійною зміною навантаження суднової електростанції для дизелів, що виконують функції допоміжних, тривалий виведення 3 експлуатації спрогнозувати досить важко. Тому для їх систем мащення найбільш ефективним $є$ процес періодичного доливання мастила. 3 урахуванням вищевикладеного метою дослідження було визначення оптимальних термінів заміні чи поповнення мастилом об'ємів системи мащення, які сприятимуть регенерації та підтриманню у встановлених межах експлуатаційних характеристик моторного мастила.

Виклад основного матеріалу дослідження. Як правило, в умовах експлуатації ДВЗ поповнення обсягу мастила циркуляційної системи мащення здійснюється шляхом доливання мастила при досягненні мінімального рівня в картері (якщо дизель 3 «мокрим» картером) або в стічній цистерні (якщо двигун з «сухим» картером). Періодичність цього процесу становить один раз на 3-5 діб, залежно від типу мастильної системи, навантаження на двигун і часу його роботи. При цьому свіже мастило, змішуючись 3 мастилом, що має певні напрацювання в дизелі, повністю не відновлює експлуатаційні та реологічні характеристики отриманої таким чином суміші. Відхилення в цих параметрах тим більше, чим більше був термін між поповненням мастила в системі [8].

Дослідження виконувалися для суднового моторного мастила Castrol TPL 203 з наступними основними характеристиками: клас в'яз-

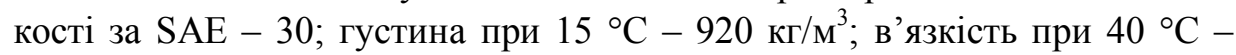
102 сСт; лужне число - $20 \mathrm{MгKОН/г;} \mathrm{призначення} \mathrm{-} \mathrm{забезпечення}$ змащування циліндро-поршневої групи і кривошипно-шатунного механізму тронкових двигунів при їх роботі на важкому паливі. Мастило Castrol TPL 203 використовувалося в циркуляційній мастильній системі суднових дизелів 6ЕY22AW фірми Yanmar, що мають такі основні характеристики: тип - чотиритактний; число циліндрів - 6 (розташування 
рядне); номі-нальна потужність - 885 кВт; частота обертання - 900 об/хв; діаметр циліндра - 220 мм; хід поршня - 320 мм. У таблиці 1 наведені дані щодо зміни експлуатаційних і реологічних характеристик мастила. При цьому параметр «реологічна стійкість» визначається як збільшення в'язкості у граничному шарі мастила порівняно з об'ємною в'язкістю і не входить до числа параметрів, рекомендованих для моніторингу фірмою виробником.

Таблиия 1

Зміна експлуатаційних та реологічних характеристик моторного мастила Castrol TPL 203 під час експлуатаціï

\begin{tabular}{|l|c|c|c|c|c|}
\hline \multirow{2}{*}{ Показник } & Базове & \multicolumn{4}{|c|}{ Час експлуатанї, години } \\
\cline { 3 - 6 } & значення & 25 & 50 & 75 & 100 \\
\hline $\begin{array}{l}\text { В'язкість (кінематична) } \\
\text { при } 50{ }^{\circ} \mathrm{C}, \text { сСт }\end{array}$ & 102 & 109 & 114 & 118 & 121 \\
\hline Реологічна стійкість, \% & $+10,36$ & $+8,76$ & $+6,38$ & $+5,95$ & $+5,44$ \\
\hline Густина при $20^{\circ} \mathrm{C}, \mathrm{\kappa г} / \mathrm{m}^{3}$ & 920 & 897 & 881 & 853 & 846 \\
\hline
\end{tabular}

Як видно 3 таблиці 1, значення всіх параметрів погіршуються і 3 плином часу та наближаються до максимально допустимих бракувальних показників. Таким чином, підтримка регламентованого часу доливання мастила в систему виводить двигун на межу надійної роботи системи, а в критичній ситуації може призвести до аварії. Саме тому виникає необхідність пошуку оптимальних термінів поповнення мастильної системи новим мастилом [9].

У зв'язку з цим під час досліджень ставилося завдання раціонального збільшення частоти доливання мастила в систему, яка визначалася шляхом контролю експлуатаційних i реологічних характеристик мастила. Його розв'язання здійснювалося безпосередньо в суднових умовах, при цьому допоміжна енергетична установка судна складалася з трьох однотипних дизелів 6EY22AW фірми Yanmar, що дало можливість проведення паралельних експериментів 3 різною інтенсивністю поповнення мастила в об'єм циркуляційної системи. Схема системи мащення дизелів 6EY22AW фірми Yanmar, що відповідає проведеним експериментам, показана на рис. 1.

Дизелі працювали навперемінки 3 практично однаковим навантаженням, діапазон якого змінювався в досить широких межах (250750 кВт), 3 однаковим часом експлуатації протягом доби (12-15 годин). Перший дизель-генератор залишався «контрольним» і зміни в частоті доливання мастила в систему на ньому не проводилися. 


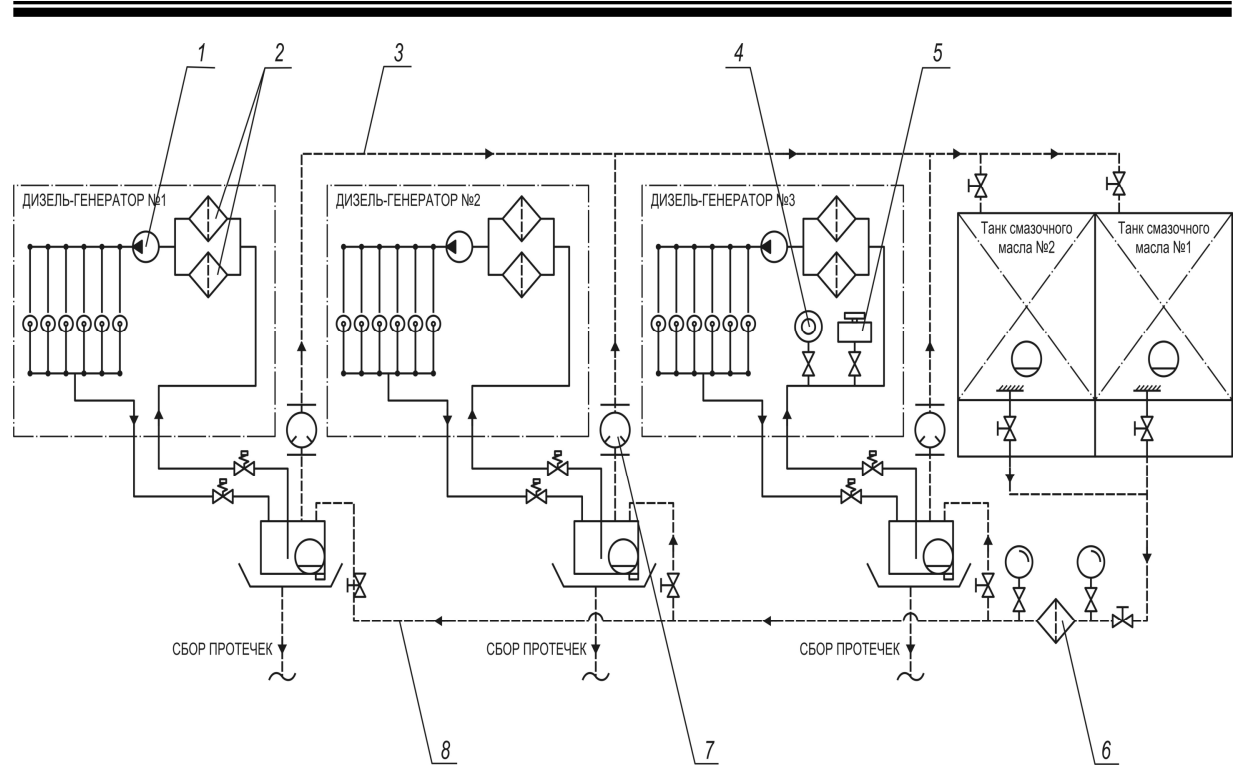

Рис. 1. Схема модернізаџї ииркуляиійної системи мащення суднових дизелів 6ЕY22AW фірми Yаптаг nід час проведення експерименту:

1 - мастильний насос; 2 -мастильний фільтр тонкого очищення;

3 - магістраль відведення парів мастила і повітря;

4 - витратомір; 5 - дозатор присадки;

6 - мастильний фільтр грубого очищення;

7 - відділювач мастила; 8 - магістраль підведення мастила

Таким чином, даний дизель працював 100 годин без поповнення системи мащення. За даний період часу кількість мастила в системі не опускалася нижче граничного рівня, а експлуатація двигуна проводилася 3 дотриманням усіх вимог, що пред'являються. У систему мащення другого дизель-генератора мастило до верхнього допустимого рівня доливалось через кожні 25 годин роботи. У систему мащення третього через кожні 10 годин при одночасному додаванні поверхнево-активної при-садки [10]. Результати, що отримані під час експерименту, наведені на рис. 2, на якому зміна параметрів наведена у відсотках.

Висновки і перспективи подалыших досліджень. 3 наведених результатів можна зробити наступні висновки.

1. При інтервалі доливання мастила 100 годин (час, який рекомендується заводом-виробником) в'язкість мастила поступово збільшує до $18,63 \%$ (при максимально можливому збільшенні цього показника $20 \%$ ), що виводить дизель на межу надійної роботи. Аналогічна тенденція спостерігається з іншими реологічними показниками моторного мастила - густиною, кислотним числом, реологічною стійкістю. 
ВІСНИК

ОДЕСЬКОГО НАЦІОНАЛЬНОГО

МОРСЬКОГО УНІВЕРСИТЕТУ
HERALD

OF THE ODESSA NATIONAL

MARITIME UNIVERSITY № $1(61), 2020$

a)

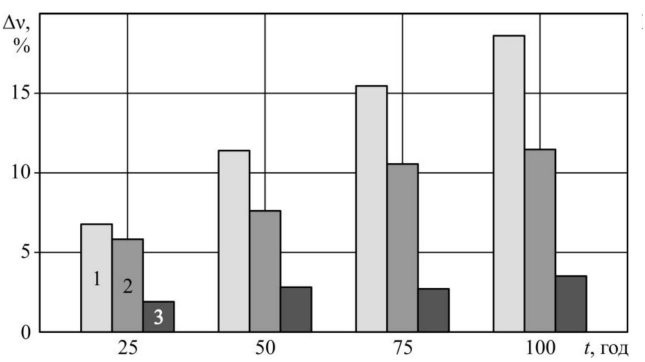

б)

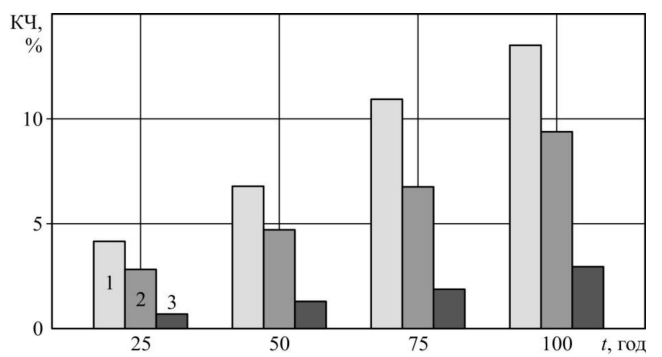

в)

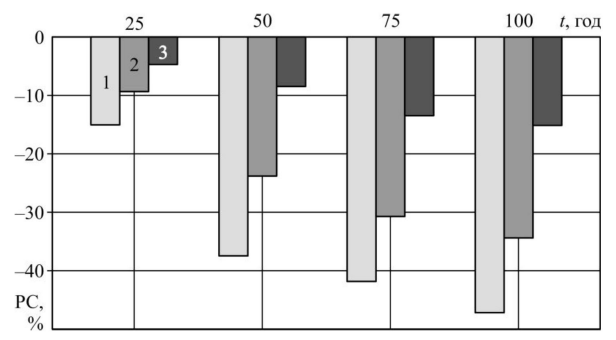

2)

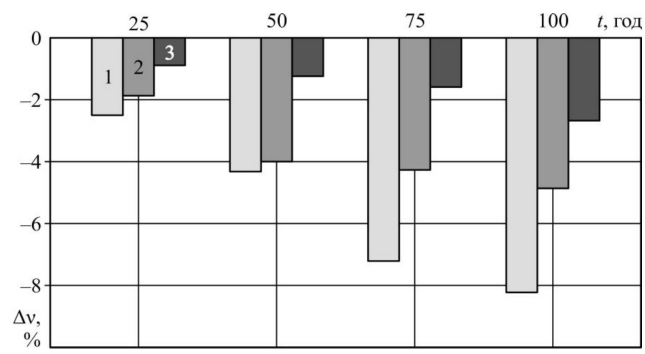

Рис. 2. Зміна характеристик моторного мастила під час експлуатачії при різній інтенсивності доливання мастила:

1 - через 100 годин роботи; 2 - через 25 годин роботи;

3 - через 10 годин роботи з додаванням поверхнево-активної присадки; а) в язкість; б) кислотне число;

в) реологічна стійкість; г) густина 
ВІСНИК

ОДЕСЬКОГО НАЦІОНАЛЬНОГО

МОРСЬКОГО УНІВЕРСИТЕТУ

№ 1 (61), 2020
HERALD

OF THE ODESSA NATIONAL

MARITIME UNIVERSITY № $1(61), 2020$

2. Збільшення інтенсивності доливання мастила сприяє більш повільному відхиленню основних якісних показників моторного мастила від базового значення, насамперед в'язкості, яка при зміні інтенсивності доливання зі 100 до 25 годин зростає на $11,76 \%$.

3. Найбільш ефективним способом регенерації експлуатаційних та реологічних характеристик моторного мастила є скорочення інтенсивності доливання мастила до 10 годин 3 одночасним використання поверхнево-активної присадки. При цьому зростання в'язкості здійснюється лише на 3,92\% при знаходженні інших показників (реологічної стійкості, густини та кислотного числа) у діапазоні рекомендованих та можливих значень.

Слід також відзначити кращий технічний стан основних поверхонь дизелів, що мають більш інтенсивний долив мастила. Наприклад, під час проведення планових моточисток дизелів було встановлено, що деталі циліндрової групи і підшипників руху «експериментальних» дизелів мають менші утворення нагарів і шорсткість поверхонь ніж «контрольний» дизель, що свідчить про більш якісний процес їх мащення. Таким чином, більш часте поповнення системи мащення та одночасне використання поверхнево-активних присадок не тільки підтримує i поновлює експлуатаційні та реологічні характеристики моторного мастила, але й сприяє більш надійній роботі суднових дизелів.

Наведені результати свідчать про позитивний вплив збільшення інтенсивності доливання мастила в систему мащення 3 одночасним використанням поверхнево-активної присадки на його експлуатаційні характеристики.

\section{СПИСОК ЛІТЕРАТУРИ}

1. Поповский А.Ю. Комплексная оценка эксплуатационных характеристик смазочных углеводородных жидкостей / А.Ю. Поповский, С.В. Сагин // Автоматизация судовых технических средств: научн.техн. сборник. 2014. Bыn. 20. C. 74-83.

2. Сагин С.В. Влияние анизотропных жидкостей на работу узлов трения судовых дизелей / С.В. Сагин, Ю.В. Заблоикий // Проблеми техніки: наук.-виробн. журнал, 2012. № 4. Одесса: ОНМУ. С. 68-81.

3. Сагин С.В. Оптические характеристики граничных смазочных слоев масел, применяемых в циркуляционных системах судовых дизелей / С.В. Сагин, Д.В. Мачкевич // Судовые энергетические установки: научн.-техн.сб. 2011. № 26. Одесса: ОНМА. C.116-125.

4. Sagin S.V. Estimation of Operational Properties of Lubricant Coo-lant Liquids by Optical Methods / S.V.Sagin, V.G. Solodovnikov // International Journal of Applied Engineering Research. 2017. Vol. 12. Num. 19. P. 8380-8391. 
ВІСНИК

ОДЕСЬКОГО НАЦІОНАЛЬНОГО

МОРСЬКОГО УНІВЕРСИТЕТУ

№ 1 (61), 2020
HERALD

OF THE ODESSA NATIONAL

MARITIME UNIVERSITY

5. Поповский А.Ю. Оиенка эксплуатационных свойств смазочноохлаждающих жидкостей судовых технических средств / А.Ю. Поповский, С.В. Сагин // Автоматизация судовых технических средств: научн.-техн. сб. 2016. Bып. 22. С. 66-74.

6. Сагин С.В. Определение триботехнических характеристик поверхностей по степени упорядоченности пристенных слоев углеводородньхх жидкостей / С.В.Сагин, Ю.В. Заблочкий // Проблеми техніки: наук.-виробн. журнал, 2011. № 3. Одесса: ОНМУ. С. 78-88.

7. Мацкевич Д.В. Диагностирование структурного состояния углеводородных жидкостей по их электрической прочности / Д.В. Мацкевич, С.В. Сагин // Проблеми техніки: наук.-виробн. журнал, 2012. № 2. Odecca: OHМУ. C. 38-46.

8. Zablotsky Yu.V. Maintaining Boundary and Hydrodynamic Lubrication Modes in Operating High-pressure Fuel Injection Pumps of Marine Diesel Engines / Yu.V. Zablotsky, S.V. Sagin // Indian Journal of Science and Technology, 2016. Vol. 9. Iss. 20. P. 208-216. DOI 10.17485/ ijst/ 2016/v9i20/94490.

9. Sagin S.V. Marine Slow-Speed Diesel Engine Diagnosis with View to Cylinder Oil Specification / S.V. Sagin, O.V. Semenov / American Journal of Applied Sciences, 2016. Vol. 13. Iss. 5. P. 618-627. DOI 10.3844/ ajassp. 2016.618.627.

10. Zablotsky Yu.V. Enhancing Fuel Efficiency and Environmental Specifications of a Marine Diesel When using Fuel Additives / Yu.V. Zablotsky, S.V. Sagin // Indian Journal of Science and Technology. December 2016. Vol. 9. Iss. 46. P. 353-362. DOI 10.17485/ijst/2016/v9i46/107516.

\section{REFERENCES}

1. Popovskii A.Yu., Sagin S.V. (2014) Kompleksnaya ocenka eks-pluatacionnyh harakteristik smazochnyh uglevodorodnyh zhidkostej [Comprehensive performance assessment of lubricating hydro-carbon fluids]. Avtomatizaciya sudovyh tehnicheskih sredstv: nauchno-tehnicheskij sbornik, no. 20, pp. 74-83.

2. Sagin S.V., Zablotsky Yu.V. (2012) Vliyanie anizotropnyh zhidkostej na rabotu uzlov treniya sudovyh dizelej [The effect of anisotropic fluids on the operation of friction units of marine diesel engines]. Problemy texniky: naukovo-vyrobnychj zhurnal, no. 4, pp. 68-81.

3. Sagin S.V., Matskevich D.V. (2011). Opticheskie harakteristiki granichnyh smazochnyh sloev masel, primenyaemyh $v$ cirkulyacionnyh sistemah sudovyh dizelej [Optical characteristics of boundary lubricating layers of oils used in marine diesel circulating systems]. Sudovye energeticheskie ustanovki: nauchno-tehnicheskij sbornik, no. 26, pp. 116-125.

4. Sagin S.V., Solodovnikov V.G. (2017) Estimation of Operational Properties of Lubricant Coolant Liquids by Optical Methods. International Journal of Applied Engineering Research, vol. 12, no. 19, pp. 8380-8391. 
5. Popovskii A.Yu., Sagin S.V. (2016) Ocenka ekspluatacionnyh svojstv smazochno-ohlazhdayushih zhidkostej sudovyh tehnicheskih sredstv [Evalua-tion of the operational properties of cutting fluids of marine technical equipment]. Avtomatizaciya sudovyh tehnicheskih sredstv: nauchno-teh-nicheskij sbornik, no. 22, pp. 66-74.

6. Sagin S.V., Zablotsky Yu.V. (2011) Opredelenie tribotehnicheskih harakteristik poverhnostej po stepeni uporyadochennosti pri-stennyh sloev uglevodorodnyh zhidkostej [Determination of tribological characteristics of surfaces according to the degree of ordering of wall layers of hydrocarbon fluids]. Problemy texniky: naukovo-vyrobnychj zhurnal, no. 3, pp. 78-88.

7. Matskevich D.V., Sagin S.V. (2012). Diagnostirovanie strukturnogo sostoyaniya uglevodorodnyh zhidkostej po ih elektricheskoj prochnosti [Diagnosis of the structural state of hydrocarbon fluids by their electric strength]. Problemy texniky: naukovo-vyrobnychj zhurnal, no. 2, pp. 38-46.

8. Zablotsky Yu.V., Sagin S.V. (2016) Maintaining Boundary and Hydrodynamic Lubrication Modes in Operating High-pressure Fuel Injection Pumps of Marine Diesel Engines. Indian Journal of Science and Technology, vol. 9, no. 20, pp. 208-216. DOI 10.17485/ijst/2016/v9i20/94490.

9. Sagin S.V., Semenov O.V. (2016) Marine Slow-Speed Diesel Engine Diagnosis with View to Cylinder Oil Specification. American Journal of Applied Sciences, vol. 13, no. 5, pp.618-627. DOI 10.3844/ajassp. 2016.618 .627$.

10. ZablotskyYu.V., Sagin S.V.(2016) Enhancing Fuel Efficiency and Environmental Specifications of a Marine Diesel When using Fuel Additives. Indian Journal of Science and Technology, vol. 9, no. 46, pp. 353-362. DOI 10.17485/ijst/2016/v9i46/107516.

Стаття надійшла до редакиії 24.01.20

Посилання на статтю: Мацкевич Д.В. Регенерація експлуатаційних властивостей моторних мастил суднових дизелів // Вісник Одеського національного морського університету: Зб. наук. праць, 2020. № 1(61). С. 121130. DOI 10.47049/2226-1893-2020-1-121-130.

Article received 24.01.20

Reference a JournalArtic: Matskevich, D. Regeneration of operational properties of marine diesel engine oils 1(61), 121-130 // Herald of the Odessa national maritime university. DOI 10.47049/2226-1893-2020-1-121-130. 